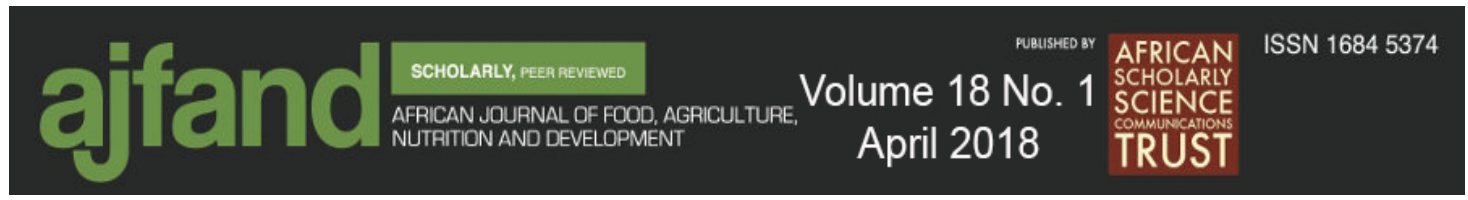

Afr. J. Food Agric. Nutr. Dev. 2018; 18(1): 13034-13051

DOI: 10.18697/ajfand.81.16400

\title{
DETERMINANTS OF INDIVIDUAL DIETARY DIVERSITY SCORE OF CHILDREN LESS THAN FIVE YEARS OLD IN THE SOUTHERN ZONE OF TIGRAY, ETHIOPIA
}

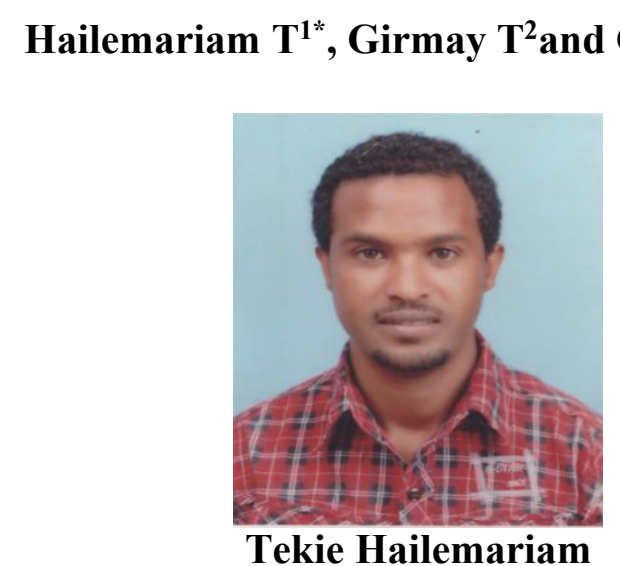

*Corresponding author email: hailet2012@gmail.com

${ }^{1}$ Department of Food Science and Post-harvest Technology, Mekelle University, Ethiopia

${ }^{2}$ Department of Natural Resources Economics and Management, Mekelle University, Ethiopia

${ }^{3}$ Department of Land Resource Management and Environmental Protection, Mekelle University, Ethiopia 


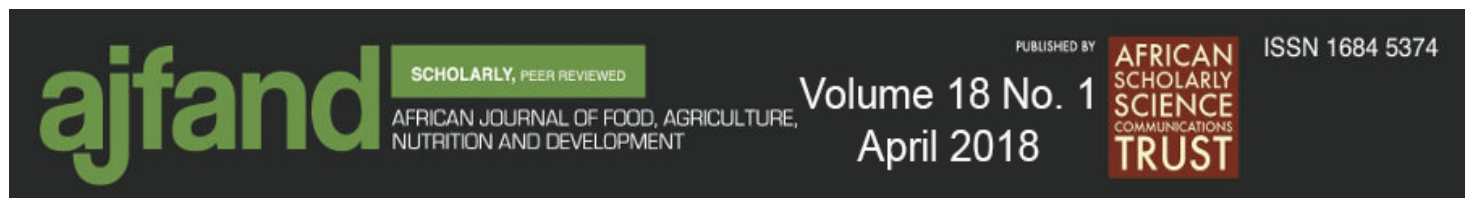

\begin{abstract}
Dietary diversity is a measure of food consumption that reflects household access to a variety of foods and is also a proxy for nutrient adequacy of the diet of individuals. Dietary diversity is useful because it is correlated with nutrient intake as well as various anthropometric measures in children. This study was carried out to assess the status of individual dietary diversity score (IDDS) of children under five years old (6-59 months) and its determinants in the Southern Zone of Tigray, Ethiopia. A survey of 320 households having children 6-59 months old was conducted using a cross-sectional descriptive study with both qualitative and quantitative study designs following the FAO guidelines for the dietary diversity and a semi-structured questionnaire for demographic and socio-economic factors. Data for the individual dietary diversity (IDDS) indicator were collected by asking the respondent (mother or caregiver) to recall the foods provided during the previous 24 hour period. Data analysis was conducted by using STATA 12 software. The mean IDDS in the study areas was found to be below four, which is the acceptable minimum level. The traditional diet of children was cereal dominated and low in micronutrient rich food groups in all the assessed Kebeles ${ }^{1}$. Being a model ${ }^{2}$ farmer, household's farmland endowment, female headship of the household, and experience in special meals preparation and participation in nutrition related training of household members were positively associated with dietary diversity of children in the study areas.In order to overcome the low IDDS of children in the areas and to improve their nutritional status through consumption of diverse foods, it is important to make agricultural production more nutrition sensitive especially on diversification of nutrient dense agricultural products.
\end{abstract}

Key words: Agriculture-Nutrition linkage, dietary diversity, food group, micronutrients, 24-hour recall

\footnotetext{
${ }^{1}$ Kebele is the lowest administrative unit which is equivalent to peasant association (PA) elsewhere

${ }^{2}$ Model farmers are those who adopt technology and new practices in the farming communities studied
} 


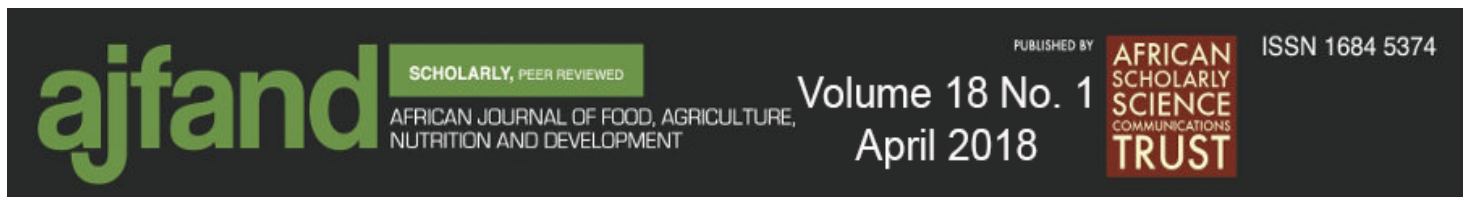

\section{INTRODUCTION}

Good nutrition and health are essential for child growth and development, body maintenance and protection from both infectious and non-communicable diseases in adult life. Adequate nutrition and a healthy productive population are increasingly recognized as an important prerequisite for poverty reduction and economic and social development [1].

Ethiopia is known for its chronic nutrition insecurity and high rate of malnutrition and its consequences. According to the Ethiopia mini demographic and health survey report of 2014, the prevalence of stunting, underweight and wasting are $44.4 \%, 28.7 \%$ and $9.7 \%$, respectively, in under-five children [2]. In the report, it was indicated that Tigray is the second most affected region in the country with $51.4 \%$ stunting, $35.1 \%$ underweight and $10.3 \%$ wasting in under-five children. One in ten children dies before the age of five and more than half of these deaths are attributed to malnutrition [3].

Deficiencies in key vitamins and minerals (collectively called micronutrient deficiencies) are also placed among the major public health problems in Ethiopia [4]. Ethiopian children aged 6-59 months are dramatically affected by vitamin A deficiency and anaemia, affecting around $61 \%$ and $54 \%$, of the children respectively [5]. Micronutrient deficiencies are caused by inadequate dietary intake, increased losses from the body, and/or increased requirements [6]. Micronutrient deficiencies are especially relevant in children since they are in a growth and development phase and have nutritional requirements that vary according to the stage of growth and which are greater and clearly differentiated from those of adults [7].

Though Southern Zone of Tigray is one of the potential areas for agricultural production, children are the most vulnerable group as reported by Bureau of Agriculture and Rural Development (BoARD) [8]. According to this report, in Raya Azebo district, 32\% of children aged 6-59 months were underweight. Besides, there are no sufficient publications regarding a comprehensive study showing dietary diversity score and nutritional status of children in the area.

Dietary diversity is considered to be a key indicator in assessing the access, utilization, and quality of diet of individuals or households [9]. The Food and Agriculture Organization (FAO) of the United Nations recommends a diet diversity score comprising eight food categories. Individual dietary diversity scores have been shown to indicate adequate nutrient intake through diet. Dietary diversity scores have been validated for several age/sex groups as proxy measures for macro and/or micronutrient adequacy of the diet [10]. Studies have also shown that an increase in dietary diversity is associated with socio-economic status and household food security [11]. Similarly, it revealed that lack of diversity in the diet is strongly associated with inadequate intake and risks of deficiencies of essential micronutrients such as vitamin A, iron, and zinc [12]. These deficiencies affect the survival, health, development, and well-being of those afflicted [12].

Hence, an assessment was conducted on dietary diversity in the Southern Zone of Tigray as a proxy indicator of the nutritional status, with the objective of identifying the status 


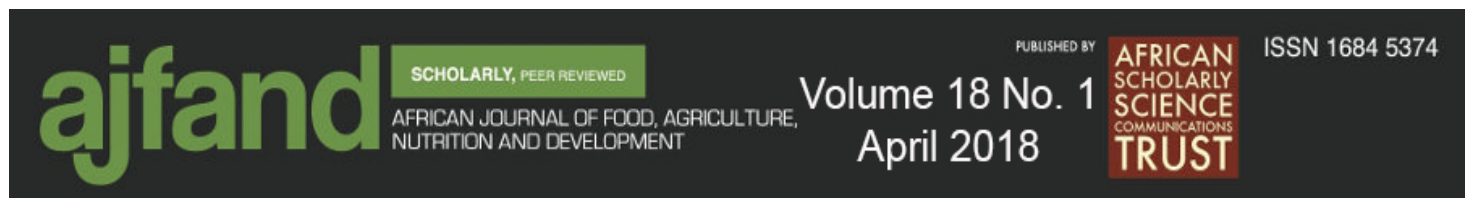

of individual dietary diversity score of children under five years old (6-59 months) and major determinants affecting dietary diversity in the areas.

\section{DETERMINANTS OF INDIVIDUAL DIETARY DIVERSITY SCORE OF CHILDREN}

Different research outputs have shown demographic and socio-economic factors to be important correlates of diet quality in children (Table 1). It was hypothesized that dietary diversity of children would show positive correlation with education status of mothers and fathers [13,14], female headship of the household [15], age of child [16, 17], endowment of land and livestock resources [13, 18], household income [13, 14, 18 - 22], knowledge and experience of household members in complementary and special meals preparation [16,21, 23 - 25], availability, access and utilization of food[26- 30], and practice of home gardening $[18,31]$. Empirical results also show negative association between DDS and family size $[14,32]$.

\section{METHODS}

\section{Study area}

This study was carried out in five districts of the Southern Zone of Tigray, Ethiopia in 2013. From each of the districts (Figure 1), four Kebeles were selected for the rapid assessment. As the study was carried out as part of baseline development for the project 'Capacity building for scaling up of evidence-based best practices in agricultural production in Ethiopia(CASCAPE),' all the ten working Kebeles of the project were included and other ten non-project Kebeles with similarity to the CASCAPE Kebeles were also selected according to the agro-ecological condition, type and status of crop production, and population numbers through discussions with zone and district agricultural offices.

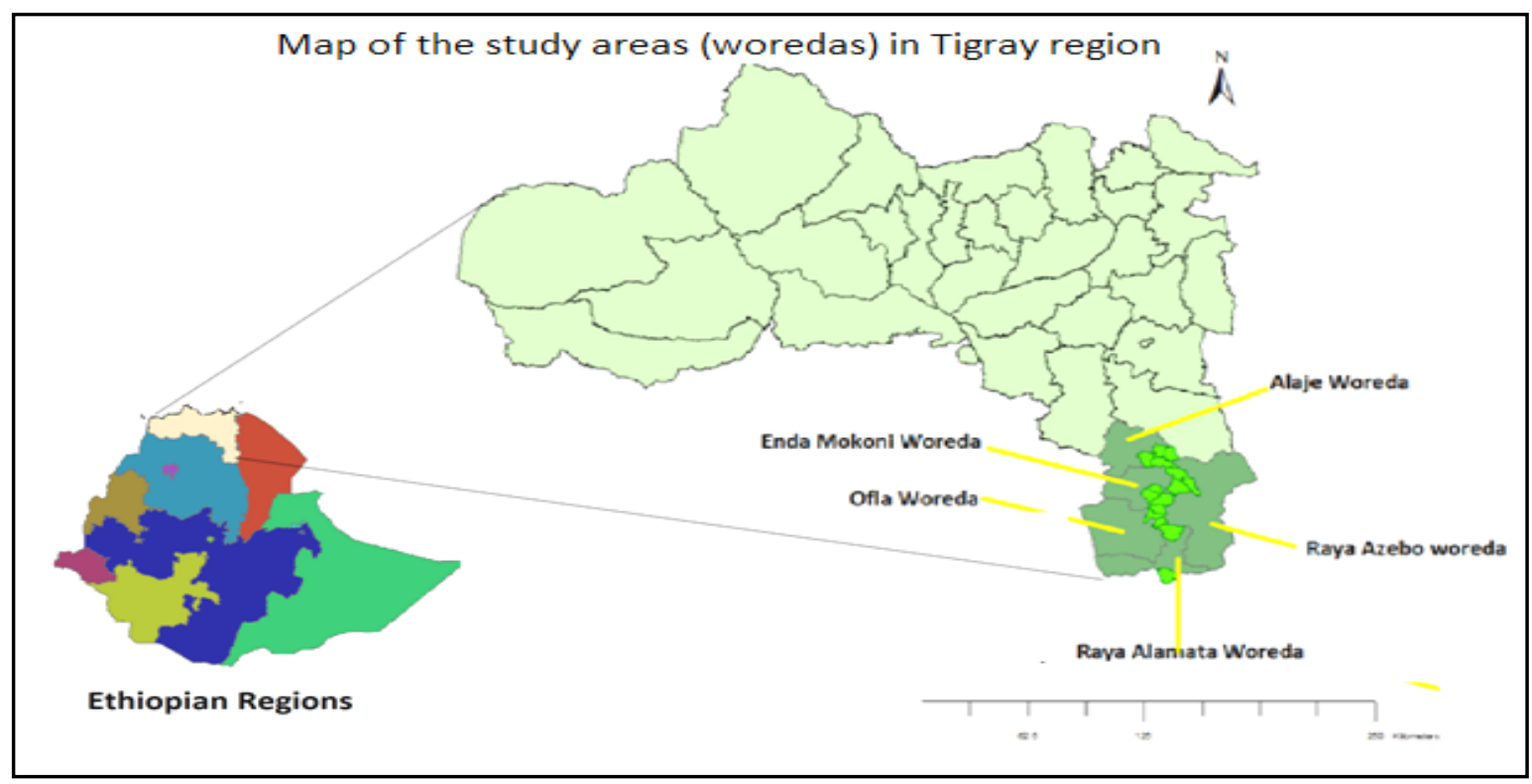

Figure 1: Map of the study area, Southern Tigray, Ethiopia 


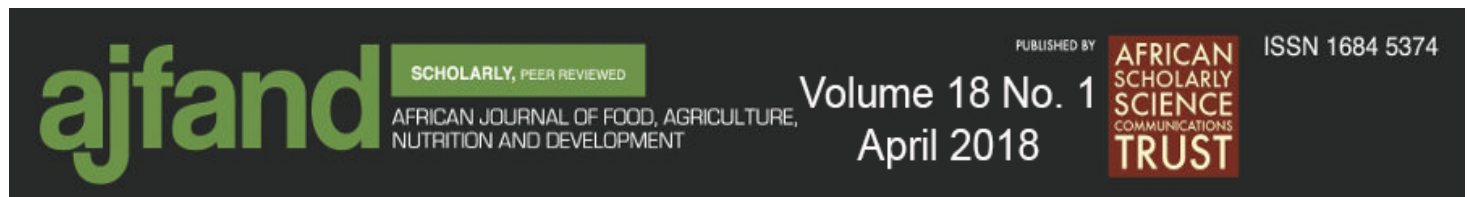

The CASCAPE Kebeles selected for the rapid assessment were: Atsela and Ayba (Alaje district); Mekan and Simret (Endamehoni district); Hashenge and Menkere (Ofla district); Tsigea and Genete (Raya Azebo district); and Garjale and Tumuga (Raya Alamata district) and the non-CASCAPE Kebeles were: Bet mera and EgriAlbe (Alaje district); Hizba-T/haymanot and EmbaHazti (Endamehoni district); Wenberet and Hayalo (Ofla district); Wargba and Hawelti (Raya Azebo district); and Laelay-dayu and Limat (Raya Alamata district). In total 20 Kebeles of the zone were assessed.

\section{Study design and sampling}

A cross-sectional descriptive study was carried out to assess dietary diversity in five selected districts of the Southern Zone of Tigray with both qualitative and quantitative study designs being used.

The population of the study included all households (HHs) in the five districts having at least one child less than five years old (6-59 months). Data for the individual dietary diversity indicator were collected by asking the respondent (mother or caregiver) to recall the foods provided during the previous 24 hours for the case child. These questions were asked to the person who is responsible for food preparation, or if that person was unavailable, another adult who was present and provided the food to the child the previous day. The questions referred to the child/children under five years old within the household. Households were chosen from the list of the total number of eligible households identified during the household listing exercise.

The sampling frame was the list of households in the land registration book of each Kebele. A total of 320 households, which is about $10 \%$ of the eligible households, with children 6-59 months were selected for the study using single population proportion formula with a $95 \%$ confidence level and $29 \%$ estimated proportion of the population with malnutrition in the areas. Out of the total sample, 160 of them were male-headed households and the rest (160) were female-headed households. Different types (clusters) of households such as female-headed model HHs, male-headed model HHs, femaleheaded non-model HHs, and male-headed non-model HHs were reached to represent the whole population. From each cluster, households were identified using systematic random sampling technique.

\section{Data collection}

Information on individual dietary diversity (food consumption) was collected using the previous 24hours as a reference period (24-hour recall). In addition to the dietary diversity, information with regard to demographic and socio-economic characteristics of the households was collected. In total, 320 households were interviewed using the template developed based on the FAO guidelines [9] for the IDDS survey and a semistructured questionnaire for the demographic and socio-economic characteristics.

\section{Data analysis}

Individual dietary diversity score data collected during the assessment were summarized into eight food groups (0-8) according to the recommendations set by FAO operational guidelines [9] for measuring dietary diversity in a standardized way of the tool originally developed by Food and Nutrition Technical Assistance (FANTA). Micronutrients of 


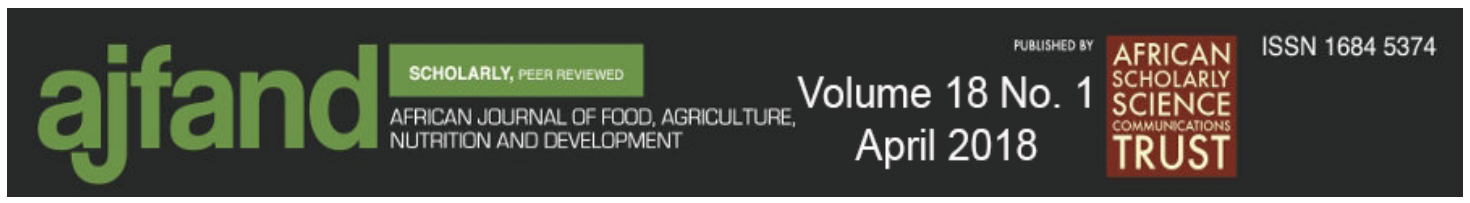

interest such as vitamin A and iron consumed by individuals from food groups that are good sources were also calculated by summing the number of specific micronutrient rich food groups consumed by the individual respondents over the 24-hour recall period. Finally, data analysis was done using Stata 12 software.

\section{RESULTS}

\section{Characteristics of study population}

Majority of the respondents were in the age range of 30-39 years (42.81\%) and age of the children less than five years old in the surveyed households was: less than 2 years (16.56\%), 2-3 years $(22.50 \%)$, and 3-5 years (60.94\%) (Table 2). Majority of the households $(70 \%)$ had only one child under five years old. The mean household size in the surveyed cohort was $5.68( \pm 1.98)$. Education level for most of the households was found to be: illiterate $(44.27 \%)$, followed by primary level of education $(36.62 \%)$. Specifically, $31.97 \%$ of fathers and $68.42 \%$ of the mothers in the assessed households were illiterate. Almost all the households are dependent on crop production $(95.3 \%)$, supplemented by livestock $(80.3 \%)$ as a secondary source of livelihood. Other sources of livelihood to the households were petty trade $(13.1 \%)$, sale of forest products $(11.5 \%)$ and casual labour $(16.6 \%)$.

\section{Individual dietary diversity score (IDDS)}

The mean IDDS of the children for the five districts of the Southern Zone of Tigray was found to be 3.56 (Figure 2). The highest IDDS was recorded for the district of Raya Alamata $(3.86 \pm 1.08)$, followed by Alaje $(3.78 \pm 0.86)$ and the lowest was Raya Azebo $(3.03 \pm 0.85)$. The average IDDS for Enda Mehoni and Ofla were 3.59 and 3.53, respectively.

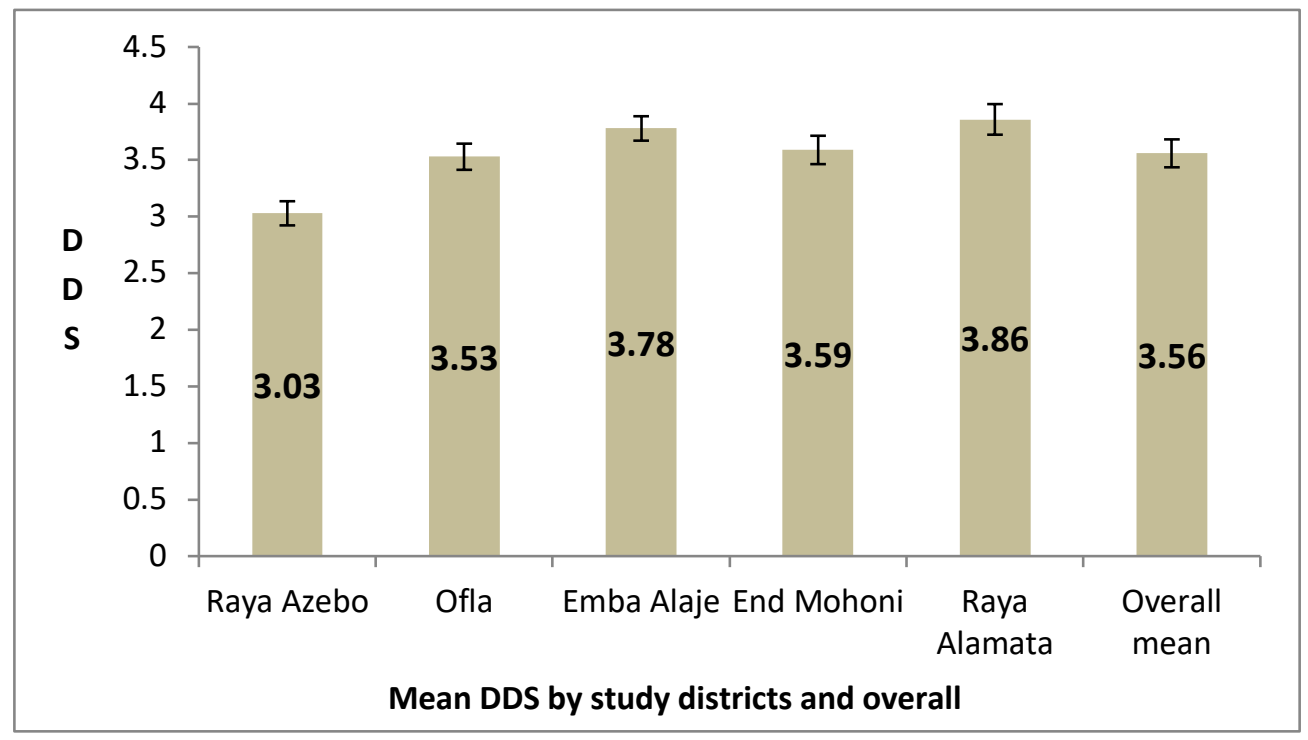

Figure 2: Individual dietary diversity scores of children in the five districts 


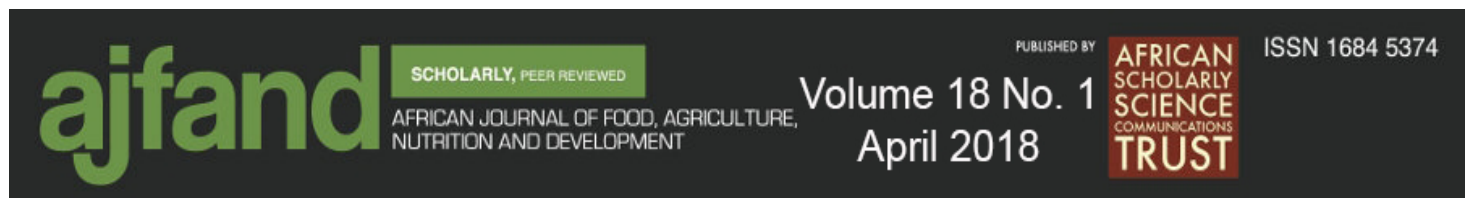

Children under five years old were classified into terciles based on the overall distribution of the dietary diversity score (low: DD $<4$ food groups; medium: 4-5 food groups; and high: 6 or more). Individual Dietary Diversity Score, using eight food groups and a 24 -hour recall period, indicate that overall $45.94 \%$ of the children in the surveyed households in the five districts had IDDS in the lowest tercile (high level of poor diets), $52.19 \%$ had their IDDS in the middle tercile (acceptable level) and only $1.88 \%$ of the children under five years assessed had high acceptable diet levels (6 or more foods).

\section{Composition of foods consumed by children}

The proportion of children who consumed one or more food types from the eight diet diversity categories the preceding day of the study was computed (Figure 3).

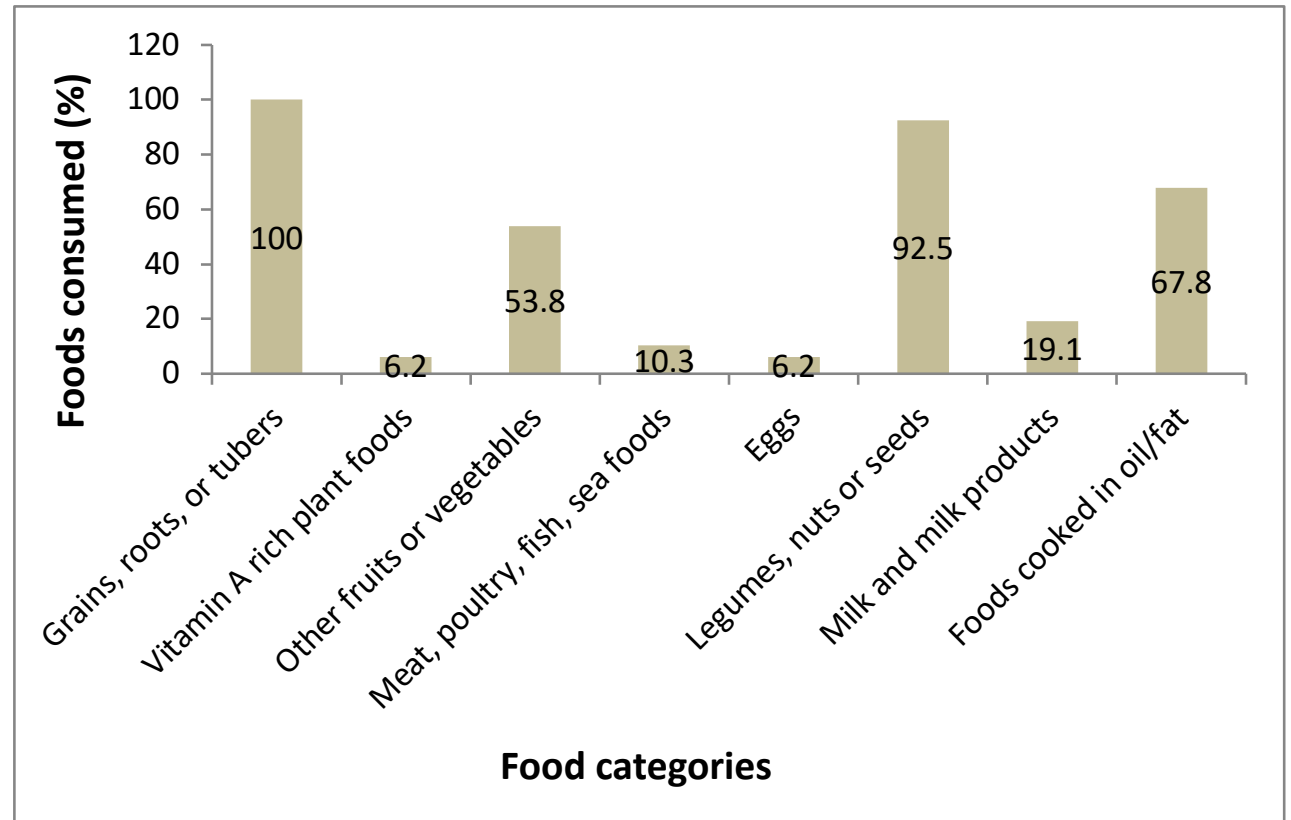

Figure 3: Composition of foods consumed by children (\%) in the previous 24 hours

The predominant food groups in the diet for the five districts were: grains, roots and tubers $(100 \%)$, pulses, legumes and nuts $(92.5 \%)$, oils and fats $(67.18 \%)$, other fruits and vegetables $(53.75 \%)$. Foods from the other remaining food groups were not frequently provided to children. These food groups are: milk and milk products $(19.06 \%)$, meat, poultry, fish and sea foods $(10.31 \%)$, eggs $(6.25 \%)$, and vitamin A rich plant foods $(6.25 \%)$. From the results obtained, all households with children under five years rely on cereals $(100 \%)$ and legumes $(92.5 \%)$ as their main foods.

\section{Micronutrient rich food products}

The micronutrient-rich food groups consumed by the children under five years old were also assessed (Figure 4). The micronutrient-rich food groups assessed were "vitamin Arich food products" and "iron rich food products" because they are the most important nutrients causing malnutrition (hidden hunger) in children under five years old in developing countries, including Ethiopia. 

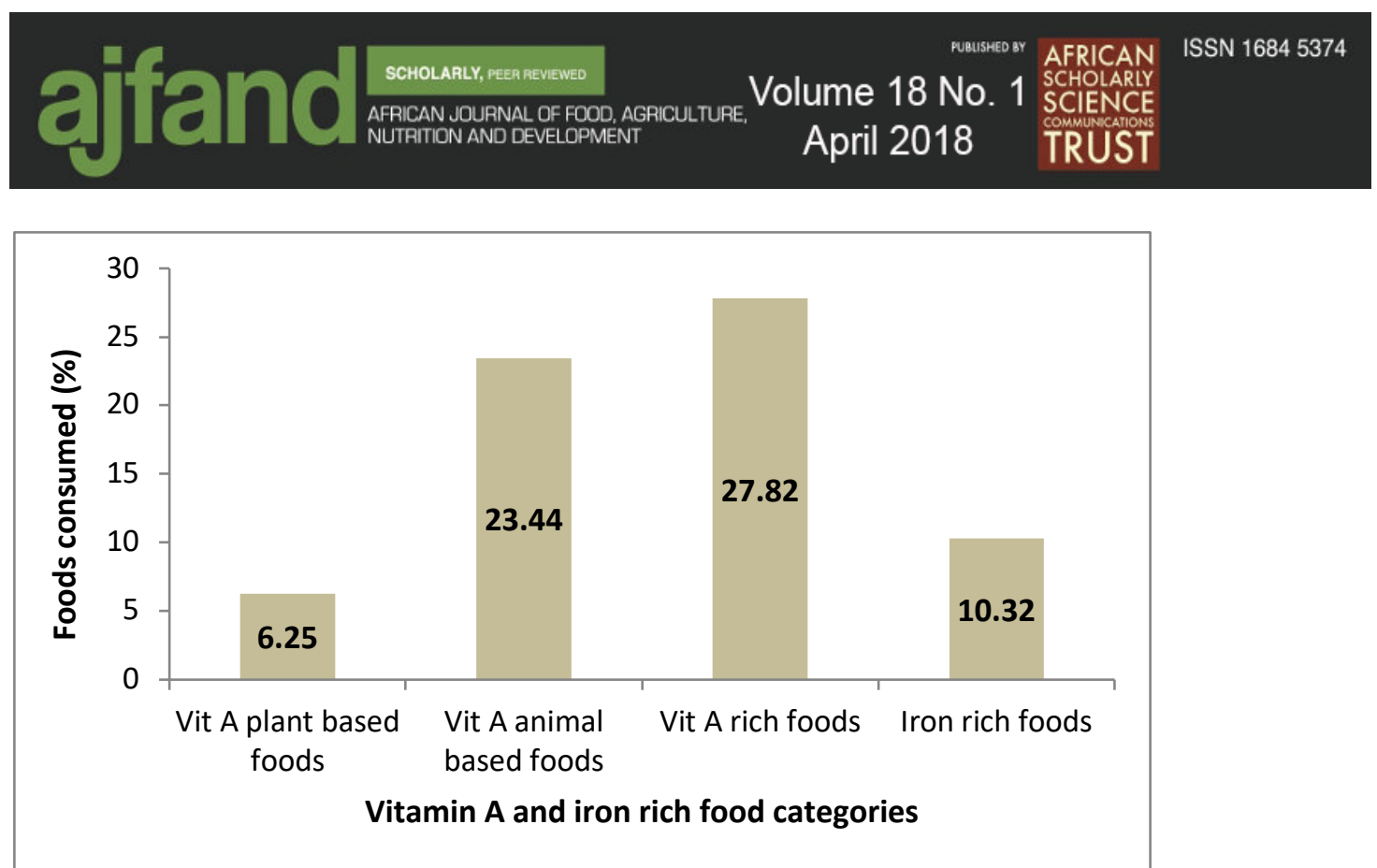

Figure 4: Vitamin A and Iron rich food products consumed by children (\%)

The vitamin A- rich food products consumed by children 6-59 months old were found to be $27.81 \%$ in the assessed Kebeles. The major source of this vitamin A was mainly animal-based food products $(23.44 \%)$ and plant-based food products $(6.25 \%)$. Iron- rich foods consumed by children were also found to be very low $(10.31 \%)$. This could be mainly due to low consumption of organ meat, flesh meat, fish, and sea foods, which are rich sources of iron. These foods are not easily accessible in the studied Kebeles.

\section{Determinants of IDDS of children less than five years old}

Table 3 presents the Poisson [33] regression model results of factors associated with the dietary diversity of children in the surveyed households. The major factors that were positively significantly associated with the dietary diversity of children in the studied areas were: the household being a model farmer $(\mathrm{p}<0.01)$, participation of household members on nutrition related trainings $(\mathrm{p}<0.01)$, better land endowment of the household $(p<0.01)$, experience of household members in special meals preparation $(p<0.05)$, and female headship of the household $(\mathrm{p}<0.1)$. The dietary diversity score was lower for children in Raya-Azebo and Enda Mehoni districts compared to those in Alaje district, showing spatial differences in the extent of child nutrition, which could be due to differences in production potential and diversity of production systems.

A household's total livestock endowment, per capita expenditure for food and drink, and ownership of garden for fruits, vegetables, and root and tuber crops did not show statistically valid influence (Table 3 ) though these were hypothesized to affect the DDS of children (Table 1). It was hypothesized that family size would affect IDDS negatively and educational status of mothers and fathers would affect it positively. However, these variables did not come up with statistically valid evidence that support the hypotheses. About $45 \%$ of households in the studied areas were found to experience food shortage at least one time in the last twelve months but did not show statistically valid association with the dietary diversity of children. 


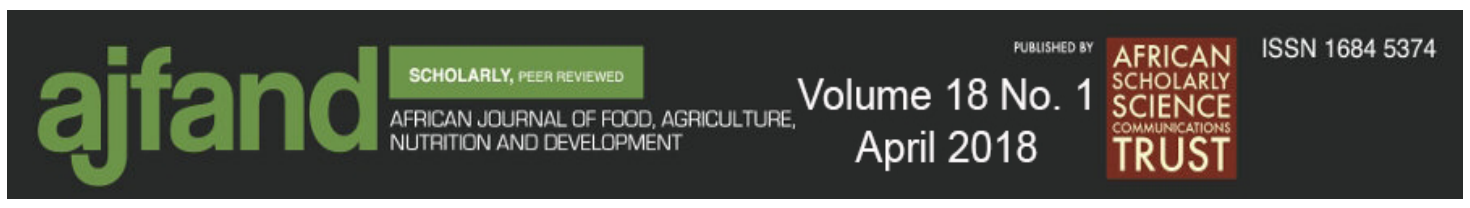

\section{DISCUSSION}

Most of the children less than five years old in the studied areas were in the age category of 3-5 years. Though children at this age require sufficient and diverse food products, the IDDS of children was found to be 3.56, which is below the acceptable standard. A similar finding was reported in Samre district, South-Eastern zone of Tigray [4], showing cereal dominant feeding habits and limited consumption of micronutrient-rich foods with low dietary diversity. This could be as a result of limited knowledge on proper feeding of children and non-availability of micronutrient-rich foods and poor economic status of the family.

The dietary diversity of children from model farmers was significantly higher than that from non-model ones $(p<0.01)$. This might be because model farmers are usually getting better food crop yield as a result of using improved technologies and resources or assets (livestock, land, agricultural implements, quality improved seeds, irrigation systems) than non-model farmers. It could also be due to the fact that they are involved in different trainings, which could have helped them know and provide different types of foods for the household. Clearly, improving the livelihoods of farmers (like in the case of model famers) can enhance the dietary diversity score of the community.

In this study, total land endowment showed a statistically significant effect on the dietary diversity, which was also anticipated to be positively related to IDDS of children. Similar research findings were reported [13] showing ownership of cultivable land positively affecting IDDS of children.

Though household expenditure for food consumption is expected to be the most important factor determining the health status of individuals, the result revealed that household expenditure showed no statistically valid effect on IDDS of children. In contrast to this, a significant effect of per capita expenditure on dietary diversity was observed [22].

Complementary feeding improvement should be of highest priority for nutrition of infants and young children because of its crucial role in preventing mortality and enhancing child development [34]. Similarly, it was reported that inadequate complementary feeding at six months was associated with impaired growth during the next 12 months, with a 37\% increased probability of stunting [35]. A significant effect was also found by the preparation of special meals on dietary diversity of children in the studied areas.

Different research outputs have confirmed that agricultural interventions failed to achieve improved nutritional status when not accompanied by nutrition education. For example, homestead gardening projects in South Africa and the HKI-HFP programme in Bangladesh reported no significant effects on child malnutrition, which later showed significant reductions in wasting among intervention communities due to nutrition education and gender considerations [36]. The finding of this study also supports the highly significant effect of training on nutrition related activities $(p<0.01)$ on dietary diversity of children. A similar conclusion was made in which dietary intake plays a critical role in maintaining optimal nutritional status, and people living with HIV/AIDS 


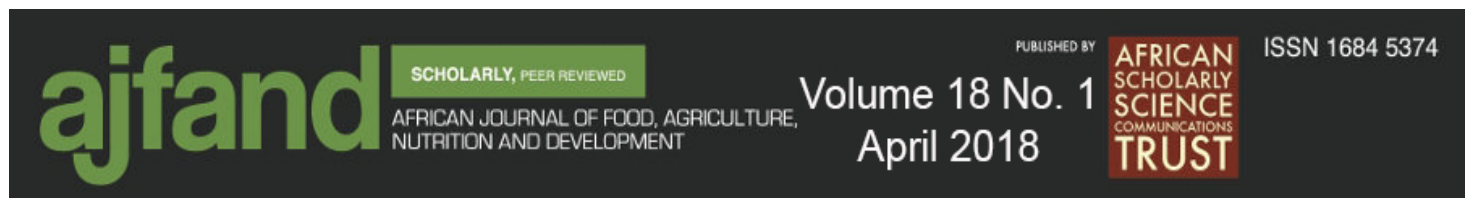

may be unable to choose and eat a varied diet if they do not possess adequate nutrition knowledge [37].

\section{CONCLUSION}

The low individual dietary diversity score results show poor child feeding practices of the studied communities. The feeding habits and practices are highly cereal dominated and children are commonly fed with food types of poor nutrient density. The average dietary diversity score (3.56) is extremely low and about half of the children did not achieve the recommended dietary diversity score. More importantly, special meals preparation and complementary feeding using different types of foods in the right proportions to improve the health status of children through nutritious and diverse food products are not common in the areas studied. Differences in geographical locations (districts), being a model farmer, better endowment of land, female headship of the household, practice of preparation of special meals, and participation of family members in training on nutrition related activities are the major factors determining dietary diversity of children in the studied areas. There should be a series of trainings and support to the farmers in the area to promote production and consumption of diverse and nutritious foods to improve dietary diversity. Increasing the number of model farmers by promoting improved technologies, offering trainings on nutrition related issues, promoting special meal preparation, and promoting and helping farmers to properly utilize their farm land could be some of the major ways to improve dietary diversity of children. Generally, in order to overcome the low IDDS of children and improve their nutritional status, it is important to make agricultural production more nutrition sensitive especially on diversification of nutrient dense agricultural products.

\section{ACKNOWLEDGEMENTS}

The authors wish to thank the technical assistants and innovation team of the Mekelle University CASCAPE project for their assistance in data collection. Special thanks go to the respondents (farmers) for their interest and valuable time in providing the information to this study. We would like to thank the Embassy of the Kingdom of the Netherlands for funding this study and the experts from the Centre of Development Innovation for their inputs in the design of this study. We are also thankful to the two anonymous reviewers for their constructive comments and inputs to improve the quality of the paper.

\section{Declaration of interest}

This study is financially supported by the Embassy of the Kingdom of the Netherlands, through CASCAPE project. We, the authors of this paper, would like to assure that we have not signed an agreement with the sponsor of the research that prevents us from publishing both positive and negative results or that forbids us from publishing this research without the prior approval of the sponsor. We declare that there is no conflict of interest in submitting this manuscript and any opinion presented in this paper is the sole responsibility of the authors. 


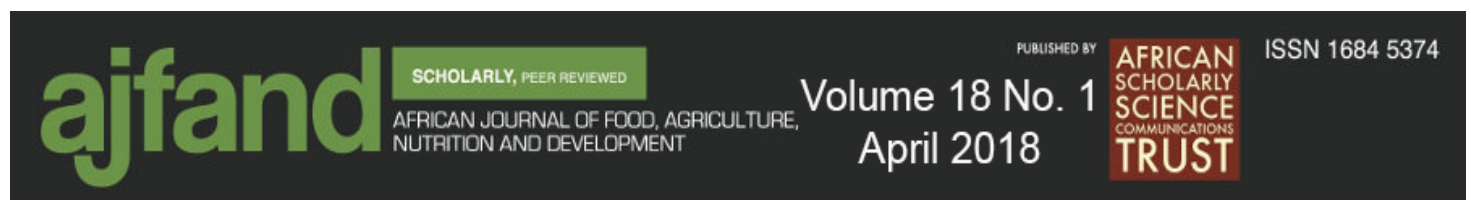

Table 1: Factors affecting IDDS of children and hypothesis used for the study

\begin{tabular}{|l|c|l|c|}
\hline Factor & Effect & Source & Hypothesis \\
\hline Mother's educational status & + & {$[12,13]$} & + \\
\hline Father's education & + & {$[13]$} & + \\
\hline Female headed households & + & {$[14]$} & + \\
\hline Age of child & + & {$[15,16]$} & - \\
\hline Family size & + & {$[13,31]$} & + \\
\hline Household income & + & {$[12,13,17-21]$} & + \\
\hline Knowledge of household members on nutrition & + & {$[20,22]$} & + \\
\hline Ownership of cultivable land & + & {$[12]$} & + \\
\hline Ownership of small-livestock & + & {$[17]$} & + \\
\hline Complementary feeding & + & {$[15,23,24]$} & + \\
\hline Availability, access, and utilization of food & + & {$[25-29]$} & {$[17,30]$} \\
\hline Access to home garden & + & & + \\
\hline
\end{tabular}

IDDS- Individual Dietary Diversity Score 


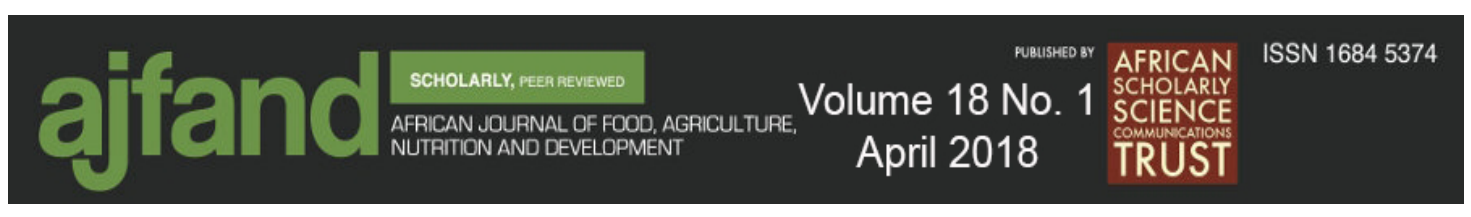

Table 2: Summary of dependent and explanatory variables

\begin{tabular}{|c|c|c|c|c|c|}
\hline Variables & Obs. & Mean & SD & Min & Max \\
\hline \multicolumn{6}{|l|}{ Dependent } \\
\hline Individual Dietary Diversity Score (IDDS) & 320 & 3.56 & 0.99 & 2 & 6 \\
\hline \multicolumn{6}{|l|}{ Independent } \\
\hline Enda Mehoni District (1 if yes, otherwise 0) & 320 & 0.2 & 0.40 & 0 & 1 \\
\hline Ofla District (1 if yes, otherwise 0) & 320 & 0.2 & 0.40 & 0 & 1 \\
\hline Raya Alamata District (1 if yes, otherwise 0) & 320 & 0.2 & 0.40 & 0 & 1 \\
\hline Raya Azebo District ( 1 if yes, otherwise 0 ) & 320 & 0.2 & 0.40 & 0 & 1 \\
\hline Alaje District ( 1 if yes, otherwise 0 ) & 320 & 0.2 & 0.40 & 0 & 1 \\
\hline Age of respondent (in years) & 320 & 35.06 & 8.82 & 18 & 69 \\
\hline Total household (HH) members (head count) & 320 & 5.68 & 1.98 & 2 & 12 \\
\hline Household head ( 1 if female) & 320 & 0.5 & 0.5 & 0 & 1 \\
\hline Model farmer ( 1 if model) & 320 & 0.5 & 0.5 & 0 & 1 \\
\hline Age of child (in months) & 320 & 43.72 & 14.18 & 5 & 59 \\
\hline Number of children under five (count) & 320 & 1.31 & 0.49 & 1 & 3 \\
\hline Education of mother ( 1 if any level of literacy) & 320 & 0.32 & 0.47 & 0 & 1 \\
\hline Education of father (1 if illiterate) & 320 & 0.32 & 0.48 & 0 & 1 \\
\hline Education of father ( 1 if primary) & 320 & 0.556 & 0.49 & 0 & 1 \\
\hline Education of father ( 1 if secondary and above) & 320 & 0.124 & 0.33 & 0 & 1 \\
\hline Experience of Food shortage ( 1 if yes) & 320 & 0.45 & 0.49 & 0 & 1 \\
\hline
\end{tabular}




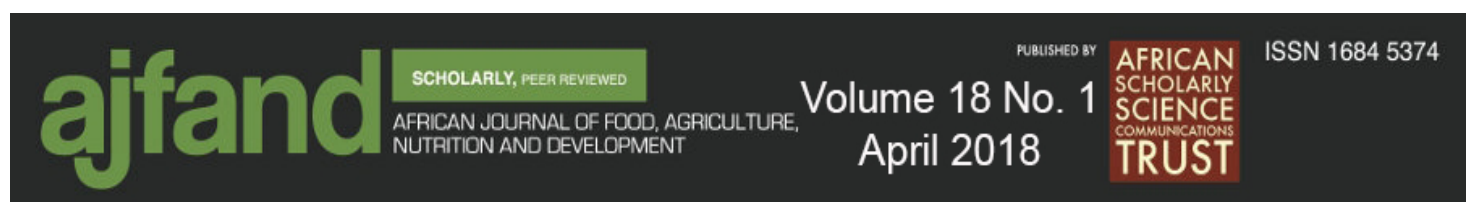

\begin{tabular}{|l|c|c|c|c|c|}
\hline Per capita cash expenditure on food and drink (in Birr) & 320 & 2654 & 1069 & 0 & 7644 \\
\hline Frequency of contact with HEW (1 if once) & 320 & 0.34 & 0.47 & 0 & 1 \\
\hline Frequency of contact with HEW (1 if twice) & 320 & 0.33 & 0.46 & 0 & 1 \\
\hline Frequency of contact with HEWs (1 if 3 and above) & 320 & 0.33 & 0.47 & 0 & 1 \\
\hline Participation on nutrition related trainings (1 if yes) & 320 & 0.24 & 0.43 & 0 & 1 \\
\hline Preparation of special meals (1 if yes) & 320 & 0.28 & 0.45 & 0 & 1 \\
\hline Total land size (in ha) & 320 & 0.57 & 0.45 & 0 & 2.5 \\
\hline Livestock endowment in Tropical Livestock Unit & 320 & 0.94 & 0.88 & 0 & 14.8 \\
\hline Experience of water scarcity (1 if yes) & & & & & 1 \\
\hline Garden fruits, vegetables, root and tubers (1 if yes) & 320 & 0.15 & 0.36 & 0 & 1 \\
\hline
\end{tabular}

Table 3: Poison regression results on determinants of the level of IDDS of children in South Zone of Tigray

\begin{tabular}{|l|l|l|l|l|}
\hline \multicolumn{1}{|c|}{ Dietary diversity score (DDS) } & \multicolumn{1}{|c|}{ Coef. } & \multicolumn{1}{c|}{$\begin{array}{l}\text { Robust } \\
\text { Std. Err. }\end{array}$} & \multicolumn{1}{|c|}{$\mathbf{z}>|\mathbf{z}|$} \\
\hline Enda Mohoni district & -0.0958 & .04981 & -1.92 & $0.055^{*}$ \\
\hline Ofla district & -0.07842 & .05235 & -1.50 & 0.134 \\
\hline Raya Alamata district & 0.01736 & .04889 & 0.36 & 0.723 \\
\hline Raya Azebo district & -0.17864 & .06582 & -2.71 & $0.007^{* * *}$ \\
\hline Age of respondent & & & & \\
\hline Total household (HH) members & 0.00275 & .00238 & 1.16 & 0.247 \\
\hline Household head (1 if female) & -0.01232 & .01201 & -1.03 & 0.305 \\
\hline
\end{tabular}




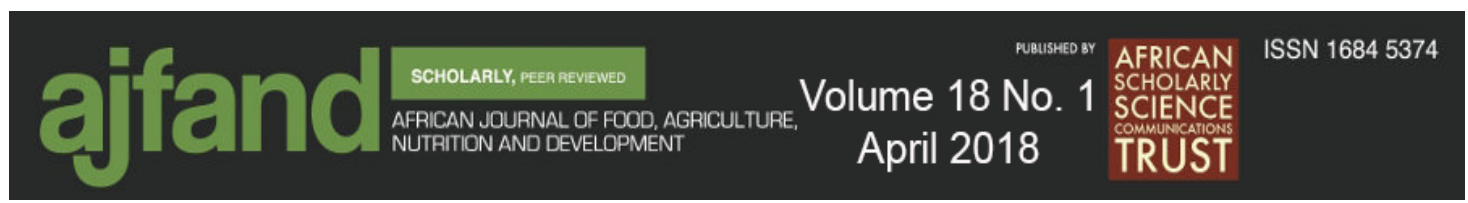

\begin{tabular}{|c|c|c|c|c|}
\hline Model farmer ( 1 if model) & 0.09584 & .03040 & 3.15 & $0.002 * * *$ \\
\hline Age of child & 0.00116 & .00123 & 0.94 & 0.348 \\
\hline Number of children under five & -0.02079 & .03264 & -0.64 & 0.524 \\
\hline Education of mother ( 1 if any level of literacy) & 0.04024 & .03593 & 1.12 & 0.263 \\
\hline Education of father ( 1 if primary) & -0.04117 & .0347 & -1.19 & 0.235 \\
\hline Education of father ( 1 if secondary and above) & -0.01465 & .06191 & -0.24 & 0.813 \\
\hline Experience of Food shortage & 0.03650 & .03458 & 1.06 & 0.291 \\
\hline Per capita expenditure on food and drink & -000003 & .00002 & -0.20 & 0.845 \\
\hline Frequency of contact with HEW ( 1 if twice) & 0.02073 & .03801 & 0.55 & 0.585 \\
\hline Frequency of contact with HEWs ( 1 is 3 and above) & 0.00085 & .04929 & 0.02 & 0.986 \\
\hline Participation on nutrition related trainings & 0.11018 & .03523 & 3.12 & $0.002 * * *$ \\
\hline Preparation of special meals & 0.06182 & .03423 & 1.81 & $0.071 *$ \\
\hline Total land size & 0.12349 & .034 & 3.62 & $0.000^{* * *}$ \\
\hline Livestock endowment in Tropical Livestock Unit & 0.00518 & .006 & 0.86 & 0.388 \\
\hline Experience of water scarcity & -0.04748 & .03521 & -1.35 & 0.178 \\
\hline Garden fruits, vegetables, root and tubers ( 1 if yes) & -0.01328 & .04595 & -0.29 & 0.773 \\
\hline Constant & 1.1092 & .10711 & 10.36 & 0.000 \\
\hline \multicolumn{5}{|l|}{ Number of observations $=250$} \\
\hline \multicolumn{5}{|l|}{ Wald chi2(23) $=128.39$} \\
\hline \multicolumn{5}{|l|}{$=0.0000$} \\
\hline Pseudo R2 & \multicolumn{4}{|c|}{$=0.0205$} \\
\hline Log pseudo ikelihood & \multicolumn{4}{|c|}{$=-417.50228$} \\
\hline \multicolumn{5}{|l|}{$=49.39524$} \\
\hline \multicolumn{5}{|l|}{$=1.0000$} \\
\hline
\end{tabular}

${ }^{* * *}$ Significant at $1 \% ;{ }^{* *}$ Significant at 5\%; ${ }^{*}$ Significant at $10 \%$; for location/districts/ Alaje is the base; for father's education illiterate is the base; HEW-Health Extension Worker 


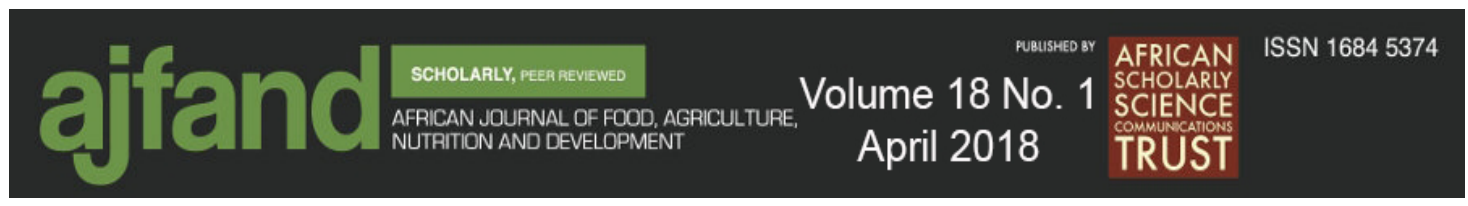

\section{REFERENCES}

1. Ellen M, Anthony $\mathbf{B}$ and $M$ Deirdre Milk and dairy products in human nutrition. Food and Agriculture Organization of the United Nations, Rome, Italy, 2013.

2. Central Statistical Agency [Ethiopia]. Ethiopia Mini Demographic and Health Survey 2014. Addis Ababa, Ethiopia, 2014.

3. UNICEF. UNICEF Ethiopia Country Statistics, 2010. (Online) Available at http://www.unicef.org/infobycountry/ethiopia statistics.html. Accessed on 12 December 2015.

4. Kiday $\mathbf{H}$, Afework $\mathbf{M}$ and $\mathbf{G}$ Meron Feeding practices, nutritional status and associated factors of lactating women in Samre district, South Eastern Zone of Tigray, Ethiopia. Nutr J. 2013; 12 (10): 12-28.

5. Laia D and R Claudia IFPRI Discussion Paper: The Impact of Irrigation on Nutrition, Health, and Gender. A Review Paper with Insights for Africa south of the Sahara Environment and Production Technology Division, 2013.

6. Adelekan DA Multiple micronutrient deficiencies in developing countries, 2003. Nutrition 19:473-474. (Online) Available at:

http://www.nutritionjrnl.com/article/S0899-9007(03)00032-7/abstract.

Accessed on 20 June 2014.

7. Prieto MB and JL H Cid Malnutrition in the critically ill child: the importance of enteral nutrition. Int J Environ Res Public Health, 2011;8:4353-4366. doi: 10.3390/ijerph8114353.

8. BoARD. Bureau of Agriculture and Rural Development Fourth quarter report by the Early Warning Response and Food Security Sector (EWRFSS). Emergency Nutrition Coordination Unit (ENCU). Mekelle, Tigray Ethiopia; 2013.

9. FAO. Food-based dietary guidelines. Rome; 2010. (Online) Available at: http://www.fao.org/ag/humannutrition/nutritioneducation/fbdg/en/. Accessed on 12 May 2014.

10. Arimond M, Wiesmann D, Becquey E, Carriquiry A, Daniels MC, Deitchler M, Fanou-Fogny N, Joseph ML, Kennedy G, Martin-Prevel Y and LE Torheim Simple food group diversity indicators predict micronutrient adequacy of women's diets in 5 diverse, resource-poor settings. $J$ Nutr. 2010; 140(11):2059S-2069S.

11. Hoddinott $\mathbf{J}$ and $\mathbf{Y}$ Yisehac Dietary Diversity as a Household Food Security Indicator. Food and Nutrition Technical Assistance Project, Academy for Educational Development, Washington, D.C. 2002. 
12. Wiesmann D, Arimond M, Becquey E, Carriquiry A, Daniels M, Deitchler M, Fanou-Fogny N, Joseph M, Kennedy G, Martin-Prevel Y and LE Torheim Simple food group diversity indicators predict micronutrient adequacy of women's diets in 5 diverse, resource-poor settings. Journal of Nutrition. 2010; 140: 2059S-2069S.

13. Rah JH, Akhter N, Semba RD, Pee S, Bloem MW, Campbell AA, MoenchPfanner R, Sun K, Badham $\mathbf{J}$ and $K$ Kraemer Low dietary diversity is a predictor of child stunting in rural Bangladesh. European Journal of Clinical Nutrition. 2010; 64: 1393-1398.

14. Tassew W and RB Jere Ethiopian Children's Dietary Diversity. Ethiopian Development Research Institute, Ethiopia; 2013.

15. Quisumbing A, Brown L, Haddad L and D Meizen-Ruth The importance of gender issues for environmentally and socially sustainable rural development. In: Lutz, E. (Ed.). Agriculture and the environment: Perspectives on sustainable rural development, The World Bank, Washington, DC, USA, 1998:186- 202.

16. Archana P, Yamini P, Neetu B, Jitesh B, Kingsley EA and JD Michael Determinants of inappropriate complementary feeding practices in young children in India: secondary analysis of National Family Health Survey 20052006. Maternal and Child Nutrition. 2012; 8: 28-44.

17. Upul S, Sanjeeva SPG, Hiranya J, Indika S and JD Michael Determinants of inappropriate complementary feeding practices in young children in Sri Lanka: secondary data analysis of Demographic and Health Survey 2006-2007. Maternal and Child Nutrition. 2012; 8: 60-77.

18. Taruvinga A, Muchenje $\mathbf{V}$ and A Mushunje Determinants of rural household dietary diversity: The case of Amatole and Nyandeni districts, South Africa, International Journal of Development and Sustainability. 2013; 2(4): 22332247

19. Regmi A Changing Structure of Global Food Consumption and Trade: An Introduction. In Changing Structure of Global Food Consumption and Trade. ERS/USDA; 2001.

20. Sanusi RA, Badejo CA and BO Yusuf Measuring Household Food Insecurity in Selected Local Government Areas of Lagos and Ibadan, Nigeria. Pakistan Journal of Nutrition. 2006; 5 (1): 62-67.

21. Nira J, Kingsley EA, Michael JD, Upul S and T Kalpana Determinants of inappropriate complementary feeding practices in young children in Nepal: secondary data analysis of Demographic and Health Survey 2006. Maternal and Child Nutrition. 2012; 8: 45-59. 


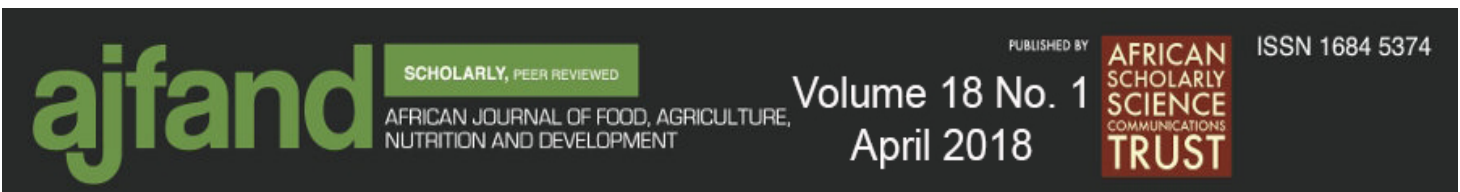

22. Andrew D How can agricultural interventions contribute in improving nutrition health and achieving the MDGs in least developed countries? Centre for Development, Environment and Policy. SOAS, University of London and Leverhulme, Centre for Integrative Research in Agriculture and Health; 2013.

23. Boulanger PM, Pérez-Escamilla R, Himmelgreen D, Segura-Millán $\mathbf{S}$ and L Haldeman Determinants of nutrition knowledge among low-income Latino caretakers. J Am Diet Assoc. 2000; 102(7): 978-81.

24. Dewey KG, Cohen RJ, Arimond M and MT Ruel Developing and Validating Simple Indicators of Complementary Food Intake and Nutrient Density for Breastfed Children in Developing Countries. Washington, DC: the Food and Nutrition Technical Assistance (FANTA) Project, Academy for Educational Development (AED); 2006.

25. Swindale A and P Bilinsky Household Dietary Diversity Score (HDDS) for measurement of household food access: Indicator guide (v.2). Washington DC. Food and Nutrition Technical Assistance (FANTA) project, Academy for educational Development. 2006: 1-9.

26. StyenNP, Nel JH, Nantel G, Kennedy G and D Labadarios Food Variety and Dietary Diversity Scores in children: are they good indicators of dietary adequacy, Public Health Nutrition. 2006; 9: 644-50.

27. Hillbrunner $\mathbf{C}$ and $\mathbf{R}$ Egan Seasonality, Household food Security and nutritional status in Dinajpur, Bangladesh, Food and Nutrition Bulletin. 2008;29: 221-31.

28. Ajani SR An Assessment of Dietary Diversity in Six Nigerian States. Afr. $J$. Biomed. Res. 2010; 13:161 -167.

29. Norhasmah S, Zalilah MS, Mohd Nasir MT, Kandiah M and AS Asnarulkhadi A qualitative study on coping strategies among women from food insecurity households in Selangor and Negeri Sembilan. Mal J Nutr. 2010; 16(1): 39-54.

30. Tefera B, David L, Abebe G, Dennis H, Carl L, Lieven H and K Patrick Food Insecurity, Food Based Coping Strategies and Suboptimal Dietary Practices of Adolescents in Jimma Zone Southwest Ethiopia; PLoS ONE 2013; 8(3): e57643.

31. Aegina B, Pura R, Juan A and S Florentino Home Gardening Is Associated with Filipino Preschool Children's Dietary Diversity. J Nutr. 2011; 111(5): 711 715 .

32. Toulmin $\mathbf{C}$ Access to food, dry season strategies and household size amongst the Bambara of Central Mali. IDS Bull. 1986; 17: 58-67. 


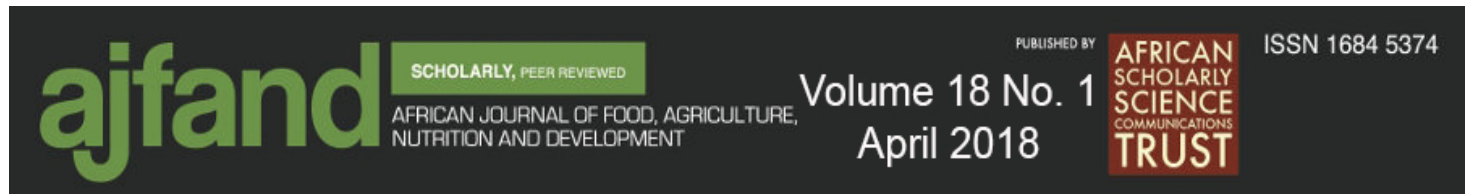

33. Long $\mathbf{J} \mathbf{S}$ and $\mathbf{J}$ Freese Regression Models for Categorical Dependent Variables Using Stata, Second Edition. College Station, TX: Stata Press.2006.

34. PAG. Protein-rich mixtures for use as weaning foods. Protein Advisory Group of the United Nations, PAG guideline No.8. New York: FAD/WHO/UNICEF; 1971.

35. Renaud B, Valériane L, Didier K, Ida V, Katia C, Patricia F, François D and $\mathbf{T}$ Marguerite Complementary feeding adequacy in relation to nutritional status among early weaned breastfed children who are born to HIV-infected mothers: ANRS 1201/1202 Ditrame Plus, Abidjan, Cote d'Ivoire; 2006.

36. Amy WG, Julie LS, Corey Mand O Olafunke The Effects of Household Food Production Strategies on the Health and Nutrition Outcomes of Women and Young Children: A Systematic Review, Blackwell Publishing Ltd, USA. Paediatric and Perinatal Epidemiology. 2012; 26: 205-222.

37. Meyer SA Measuring the Potential for Malnutrition in People with the Human Immunodeficiency Virus. Florida Dietetic Association, Palm Beach, FL; 1994. 